\title{
Commentary
}

\section{Speech disorders of Parkinsonism: a review}

\author{
EMR CRITCHLEY \\ From the Preston Royal Infirmary, Preston, Lancashire
}

SUMMARY Study of the speech disorders of Parkinsonism provides a paradigm of the integration of phonation, articulation and language in the production of speech. The initial defect in the untreated patient is a failure to control respiration for the purpose of speech and there follows a forward progression of articulatory symptoms involving larynx, pharynx, tongue and finally lips. There is evidence that the integration of speech production is organised asymmetrically at thalamic level. Experimental or therapeutic lesions in the region of the inferior medial portion of ventro-lateral thalamus may influence the initiation, respiratory control, rate and prosody of speech. Higher language functions may also be involved in thalamic integration: different forms of anomia are reported with pulvinar and ventrolateral thalamic lesions and transient aphasia may follow stereotaxis. The results of treatment with levodopa indicate that neurotransmitter substances enhance the clarity, volume and persistence of phonation and the latency and smoothness of articulation. The improvement of speech performance is not necessarily in phase with locomotor changes. The doserelated dyskinetic effects of levodopa, which appear to have a physiological basis in observations previously made in post-encephalitic Parkinsonism, not only influence the prosody of speech with near-mutism, hesitancy and dysfluency but may affect word-finding ability and in instances of excitement (erethism) even involve the association of long-term memory with speech. In future, neurologists will need to examine more closely the role of neurotransmitters in speech production and formulation.

"In the great majority of cases of paralysis agitans, disorders of speech become obvious as the disease advances. The shades of inflection to emphasise a point disappear, the volume of the voice is reduced, pronunciation of consonants is defective and the sentence often ends in a mumble. From a monotonous, soft voice without variation in pitch, there is gradual progression of the dysarthria until the patient's diction may become neither audible not intelligible. Whereas the general slowness of movements finds its expression also in the rate of speech in some cases, others talk fast, running words into each other as if they wanted to conserve their energies and get it over and done with. A few exhibit a progressive acceleration of words towards the end of a sentence similar to the festination of gait."1

Each epoch from the epidemic of encephalitis lethargica to the post-levodopa era has posed fresh

Address for reprint requests: Dr EMR Critchley, Royal Infirmary, Preston, Lancs PR1 6PS, UK.

Accepted 10 July 1981 problems, adding to the complexity of the speech disorders accompanying the disease. Adolescents developing a Parkinsonian syndrome in the late stages of epidemic encephalitis used to present with bizarre fluctuations in motility (kinesia paradoxica) and respiration. ${ }^{2}$ Many of them were rigidly immobile, or unable to stand without support, for much of the day and yet could show full freedom of movement at night, dance gracefully in response to a rhythmic stimulus and even run better than they could walk. As well as oculo-gyric crises, they suffered from recurrent respiratory crises with a multiplicity of disturbances affecting the rate and rhythm of respiration. Rapid, deep and violent respirations could be followed by tetany, prolonged apnoea, cyanosis and convulsions. Alternatively, attacks of Cheyne-Stokes respiration, accompanied by strange and distorted posturing, could be provoked by trivial stimuli. ${ }^{3}$ These problems of mobility and respiration were reflected in their speech. In the older, end-stage postencephalitic Parkinsonian patient, Martin, Hurwitz and Finlayson ${ }^{5}$ observed the 
negative features of the disease. Many were absolutely inarticulate, others rarely spoke and more than half were incomprehensible when they did speak. Their difficulties, which stimulated the results of experimental bilateral pallidal damage, included akinesia, apraxia and deficiencies of postural fixation of the tongue. The introduction of stereotaxic surgery brought a new series of complications. Dysarthria or dysphonia following operation could be permanent, but anomia or aphasia were more usually transitory. Finally, the appearance in the post-levodopa era of dyskinesias, "on-off" fluctuations and peak-dose dysphonia suggest that in some respects the disease has completed a full circle.

Conventionally, speech disturbances found in Parkinsonism are labelled dysarthrias. But only Lenneberg $^{6}$ is prepared to ascribe these to a purely articulatory disturbance-an "adiodochokinesia of the voice". 7 "There may be a dramatic impoverishment of all articulatory muscles. Instead of the required rapid changes in the spatial geometry of the vocal tract, a relative rigidity allows for practically no changes in the oral configuration resulting in monotonous inarticulate utterances. The dysarthria is merely a concomitant of a condition that affects all facial and oral movements". Luchsinger and Arnold ${ }^{8}$ describe spastic rigidity of articulatory and phonatory musculature: "The same disorders of drive afflict all parts of the peripheral speaking apparatus. This means that respiration, phonation, articulation and diction are similarly disturbed"; and Calne ${ }^{9}$ emphasises that the "control of the larynx and respiratory muscles is defective".

To encompass this complex disturbance of speech, Peacher ${ }^{10}$ and Grewel ${ }^{11}$ suggested "dysarthro-phonia" and "dysarthro-pneumophonia", respectively; but a wider definition of dysarthria as any disturbance of speech that has as its basis some type of neuromuscular abnormality is preferable. ${ }^{12}$ It is possible, thereby, to omit deviant patterns of pitch, intensity and speech rhythm that have a structural or psychological basis and yet include dysprosody, dysphonia and any speech deviation resulting from paresis of the respiratory muscles. ${ }^{12-14}$ Even so, many speech abnormalities found in Parkinsonism-festination, different kinds of hesitation, mutism, oral and articulatory apraxias, and akinesia for speech-lie outside this definition.

\section{Physical production of speech}

Since the advent of levodopa and the decline in the incidence of postencephalitic Parkinsonism, the speech disorders of Parkinson's disease have been relatively neglected. Although a treated patient may have a specific dyskinesia of some of the muscles of articulation, few untreated patients exhibit a dysarthria restricted to a disorder of articulation. The progression of symptoms as observed by Darley, Aronson and Brown ${ }^{13} 14$ monopitch, reduced stress, monoloudness, imprecise consonants, inappropriate silences, short rushes and harsh breathless voicesuggests an impairment of phonation; but patients when asked to describe why they have difficulty with speech invariably describe their facio-oral difficulties, "my tongue thrusts out" or "my chin shakes and my cheeks suck in", even in the presence of obvious dyspnoea and dysphonia.

Dysphonia results from impaired control of respiratory and laryngeal muscles. Parkinson ${ }^{15}$ noted that one of his patients "fetched his breath rather hard". Intermittent or paroxysmal respiratory abnormalities in the postencephalitic patient were described in the introduction. More usually there is an increased uniformity of phonic respiration due to muscular rigidity.$^{16}$ Rigidity may be such that the respiratory organs remain in a fixed, neutral position during speech apart from limited, synchronous movements of the pectoral and diaphragmatic muscles. The respiratory strength is decreased with a reduction in vital capacity. ${ }^{17}$ Progression of the disease brings dyspnoea on mild exertion and the maximum breathing capacity may fall to $56 \%$ of the predicted norm in the absence of other thoracic or systemic disease. ${ }^{18}$ The uniformity of respiration is punctuated by abnormally deep respirations, representing $9 \%$ of the respiratory excursions. ${ }^{16}$ Deeper respirations occur at rest without obvious cause, or before attempting to talk. They are often succeeded by slowing of respiration, producing characteristic plateaus ${ }^{8}$ and, when talking, festination or fading of speech results.

In normal human speech the mobility of the vocal cords and their ability to alter in shape and dimension provides a wide range of notes varying in pitch, quality and intensity. During phonation the adducted cords are set in vibration. These vibrations involve either segments of the cord or its entire length. The air-stream is cut up into a series of rapid puffs producing a tone, and the duration of the closed contact of the cord varies with the pitch of the note produced. ${ }^{19}$ In Parkinsonism there is a breakdown of prosodic factors, glottal closure may be incomplete, the vocal tone breathy, harsh and low pitched, and adduction or abduction of the cords may be faulty. ${ }^{12}$ The intratracheal pressure during normal conversation may be reduced with little fluctuation in amplitude and rigidity, or sluggishness of vocal cord movement may be confirmed by laryngoscopy. With mild impairment, abduction for inspiration occurs promptly but adduction for phonation is slow: if severe, rigidity affects both 
abduction and adduction and tremor of the cords, similar to tremor of the extremities, has been observed. 8

Normally more than a hundred muscles are involved in articulation, producing phonemes at a rate of 14 per second. Thus, several hundred individual muscular events-contraction, relaxation or maintenance of tone-occur every second. ${ }^{6}$ In Parkinsonism the most common defect in articulation is an unnatural regularity and equality of articulatory movement produced by stiffness of facial, oral, buccal and pharyngeal muscles ${ }^{8}$ and resulting in a hypokinetic dysarthria. ${ }^{13} 14$ Particularly in postencephalitic Parkinsonism, additional fragmentary, repetitive, involuntary or quasicompulsive disorders of movement occur, incompletely masked by the more organised manifestations of tremor, rigidity and bradykinesia. ${ }^{20}$ Included among these fragmentary disorders are tongue thrusting, disorders of postural fixation of the tongue with inattention and neglect, ${ }^{5}$ disorders of the rate of articulation, ${ }^{22}$ and palatal paralysis. ${ }^{8}$ However, the more usual pattern of dysfunction begins posteriorly with laryngeal impairment and progresses anteriorly until, ultimately, the lips are also involved. ${ }^{22}$ The march of dysfunction has been documented in 200 patients by means of the FisherLogemann sentence articulation tests. ${ }^{22}$ Only $11 \%$ of all patients were without any defect of speech. $45 \%$ had laryngeal dysfunction as their only manifestation, $13.5 \%$ also had impairment of the posterior portion of the tongue, and in $17 \%$ movements of the anterior half of the tongue - the tongue bladewere also affected. Labial misarticulations were associated with other defects in a further $5.5 \%$ and the disorder had spread to involve lips and tongue tip in an additional $9 \%$. Not one of the 200 patients showed labial or lingual dysfunction as their sole manifestation. Apart from this progression of dysfunction, Logemann et $a^{22}$ report a nasal tone to the voice in $10 \%$ of their series. According to Luchsinger and Arnold, ${ }^{8}$ hypernasality of speech may be due to paresis of the palate, giving an open rhinolalia, or to seemingly increased strength or rigidity of palatal closure, producing closed rhinolalia. The tidy progression of symptoms in Logemann's patients, most of whom had relatively mild idiopathic Parkinsonism, was not apparent in the 130 postencephalitic patients examined by Martin et al. ${ }^{5}$ The abnormalities most clearly responsible for their greatly impoverished ability to communicate were rigidity of larynx, gross disorders of postural fixation of tongue and associated involuntary movements, and irregularity and weakness of respiration.
Joubert and Barbeau ${ }^{23}$ emphasise the importance of akinesia, the "unsticking" of muscles, in all motor performance and relate this symptom to two divergent yet complementary definitions: "Akinesia is a defect in the initiation of movement", ${ }^{24}$ "Akinesia is a manifestation of muscular weakness and is expressed by fatiguability in repetitive movements". ${ }^{25}$ Varous facets of their anaylsis apply to the speech of Parkinsonian patients. There is prolongation of the "execution or initiation time" of speech. Early fatigue comes from difficulties in changing motor patterns whilst in motion. As a result, more errors are made when speaking. Defects in discriminatory perceptions or sensory feedback suggest tactile agnosia whilst defects in synchronisation mimic apraxia. A far simpler approach, avoiding the uncertain boundaries between akinesia, feedback mechanisms and apraxia, is to regard akinesia as an aspect of rigidity.

\section{Rate of speech}

The speech disturbances of Parkinsonism have been classified symptomatically into akinetic, hyperkinetic, rigid and iterative (repetitive) forms, 2627 thus reflecting the predicament of the rest of the body's musculature. Various combinations of akinesia and rigidity are most common, but other disorders of prosody and speech speed, such as inappropriate silences, short rushes of speech and variations in rate, affect $20 \%$ of patients. ${ }^{22}$ As with skeletal muscles, single movements are slow but repetitive movements tend to be abnormally fast with very limited range. ${ }^{13} 14$ Thus the rate of speech tends to be variable and often slightly faster than normal, contrasting with the slow dysarthrias characteristic of other extrapyramidal syndromes. The variability in rate suggests a conscious desire to overcome physical difficulties, for example, to complete a sentence during an expiratory plateau. Similarly, in the initiation of speech, great physical effort may be needed to release the rigidity of articulatory and phonatory musculature. But two phenomena, kinesia paradoxica and palilalia, provide ample evidence of the importance of cerebral mechanisms in controlling the rate of articulation. Four different forms of kinesia paradoxica occur in Parkinsonism: (1) diurnal fluctuation in performance as in the early postencephalitic patients, (2) temporary ability to respond to external stimuli, (3) temporary ability to respond to a crisis or emotional disturbance, for example to run from a fire, and (4) violent oscillations in performance following levodopa therapy.

Kinesia paradoxica may involve locomotion or speech. A patient who normally walks with small 
steps or festinates may be able to stride out in response to the ocular stimulus of parallel lines such as railway sleepers, or to the auditory stimulus of a dance band. A patient with an almost unintelligible dysarthria will, if urged, repeat single words clearly and loudly, or count slowly and distinctly from one to ten. As soon as he resumes spontaneous expression, rate increases, volume falls and words become slurred. Another patient with marked festination of speech may be able to space his words and pronounce them correctly whilst singing. ${ }^{1}$ Control of the rate of locomotion or speech in response to an external stimulus must occur through reflex activity at cerebral level.

Palilalia (auto-echolalia) is a compulsive tendency to psychomotor propulsion manifesting itself in accelerated speech. The patient repeats the last word or two (or syllables) of a verbal statement. The words tend to be uttered more and more quickly, and with less distinctness, so that the latter part may trail away inaudibly. The phenomenon occurs most frequently with postencephalitic Parkinsonism and with pseudobulbar palsy resulting from vascular lesions. ${ }^{28}$ Palilalia may also occur with idiopathic Parkinsonism, neurosyphilis, degenerative disease, demyelination, traumatic encephalopathy and as an isolated familial disorder. ${ }^{29}$ The pathological lesion was presumed to involve the striatum, $^{8}$ but Alajouanine et $a l^{\mathbf{3 0}}$ observed palilalia occurring paroxysmally after seizures arising from the supplementary motor area. In the course of stereotaxic surgery for Parkinsonism, Guiot et $a^{31}$ noted that stimulation of the ventrolateral nuclei of the thalamus near the thalamocapsular boundary could modify speech either by stopping it or by hastening its delivery. There was a progressive augmentation of the speed of enunciation, accompanied by progressive diminution of the sound of the voice, the last words becoming almost inaudible. The patients described the effect, which could be obtained at a lower threshold of stimulation than that needed for arrest of movement, as "something in me which forces me to hurry" .. . "like an instinct to go faster".

\section{Content of speech}

The utterances of most Parkinsonian patients are unexceptional but, as the disease progresses, articulation may become so limited that the differentiation between aphonia, anarthria and akinetic mutism is one of emphasis. However, a few patients with the metencephalic type of postencephalitic syndrome, choreic disturbances, respiratory troubles and frequent oculogyric crises may exhibit a wide range of hyperkinetic disorders including palilalia, echolalia (the forced repetition of someone else's words again and again), and even coprolalaia. ${ }^{32}$ Dystonic or dyskinetic movements may be associated with explosive utterances, crying out loud or shrieking (klaxophonia) and talking in a far louder voice than usual (megaphonia). The early literature also included examples of tachyphemia (the tendency to rapid, stereotyped talk), logorrhoea and verbigeration. ${ }^{32}$

Sporadic examples of the postencephalitic syndrome still occur and live up to the descriptions in the older textbooks. For the most part, these patients have learnt to be wary of hospitals and they, or their relatives, frequently relate bitter experiences of attempts to stabilise them on increasing doses of levodopa. In 1970, Sacks and Kohl ${ }^{33}$ described "incontinent nostalgia" in a 63-year-old female who had had progressive postencephalitic Parkinsonism since the age of 18 years. Levodopa therapy resulted in a dramatic release from her Parkinsonism and oculogyric entrancement. She requested a tape recorder and over the next few days recalled the night clubs and music halls of her youth. When the increased excitement necessitated a reduction of the dosage of levodopa, she instantly "forgot" all these early memories. The authors quote a patient of $\mathrm{Zutt}^{34}$ who complained of "thousands of memories suddenly crowding on to his mind" during a memory surge occurring spontaneously whilst in an oculogyric crisis.

\section{INFLUENCE OF TREATMENT UPON SPEECH}

\section{Stereotaxic surgery}

Stereotaxic operations have had an established place in the treatment of Parkinsonism since Cooper ${ }^{35}$ showed that infarction of the globus pallidus resulting from anterior choroidal ligation improved contralateral rigidity and tremor. Despite the advent of levodopa, stereotaxic operations are sometimes indicated for dystonias and unilateral or intractable tremors. The aim of operation is to interrupt the ansa and fasciculus lenticularis as strategically and completely as possible by placing lesions in the vincinity of the ventrolateral nuclei of the thalamus, the posterior limb of the internal capsule or the globus pallidus. A double ipsilateral thalamocapsular and pallidocapsular lesion has become the standard procedure in some departments. ${ }^{36}$ In general, tremor is alleviated best by thalamocapsular lesions and rigidity by pallidocapsular lesions. Several techniques are used, thermocoagulation, crythalamotomy (freezing) or the earlier chemopallidectomy (injection of alcohol). The bigger the lesion, irrespective of site, the greater the risk of neurological deficit and postoperative complications 
such as haemorrhage into the lesion.

Stereotaxic surgery can be performed under light premedication enabling speech, tremor and movement to be monitored before a permanent lesion is placed. A routine of question and answer evoking spontaneous speech and testing naming ability is carried out. If there is any alteration of speech performance, the stylus is withdrawn but may be reintroduced elsewhere. Unfortunately, despite careful monitoring, the effect of operation upon the speech of Parkinsonian patients is variable. Some improvement may occur and can be predicted where the preoperative speech deficit is mainly due to rigidity of chest, jaw and tongue $; 36$ but for most patients the speech disorder either worsens or remains unchanged, and patients have to be warned before operation of a possible deterioration in performance. ${ }^{37}$ Dysarthria and dysphonia may be permanent complications of surgery. The nasal quality of the voice may be exaggerated and, rarely, there may be an increased difficulty in starting to speak. ${ }^{38}$ Where speech is unimpaired preoperatively, the risks of serious deterioration are slight and patients may accept a mild deterioration in voice volume and articulatory clarity in return for an improvement in limb function; but if voice volume or articulation is already poor a further deterioration is more liable to occur. Therefore any serious disorder of speech constitutes an absolute contraindication of surgery. ${ }^{1}$ The risk of speech disturbances increases with bilateral surgery and constitutes the major disadvantage of this procedure. In the long-term follow up of bilateral operations, Krayenbühl et al, ${ }^{39}$ and Bell ${ }^{38}$ reported an aggravation of speech difficulties, notably dysarthria and dysphonia, in 60 to $70 \%$ of patients operated.

Such complications are essentially exaggerations of the usual speech pathology encountered in Parkinsonism; but mutism, hesitancy and dysfluency of speech, or even aphasia may follow operation as transient phenomena. The anatomical basis for these abnormalities has been confirmed from studies of thalamic haemorrhage, thalamic tumours and histologically verified stereotaxic operations. ${ }^{40}$ Stereotaxic stimulation of thalamic structures may result in arrest or acceleration of speech, ${ }^{31}$ spontaneous speech consisting of either brief yells or compulsory utterances combined with stereotyped movements, ${ }^{41}$ naming errors, perseveration with repetition of the correct object name or repetition errors with reduplication of the wrong answer, and occasionally "true" aphasia. ${ }^{42}$ The nature of the deficits in higher language functions that can result from stereotaxic stimulation or surgery is still a matter of controversy. ${ }^{42} 43$ Anomia has been defined as loss of speech fluency ${ }^{44}$ and as inability to name objects correctly with retained ability to speak. ${ }^{45}$ There is also a difference in character between anomia following pulvinar lesions-resembling nominal aphasia with paraphrasia-and anomia from lesions of the contiguous areas of the posterior, inferior medial portion of the ventrolateral thalamus, in which case the patient is unable to find the right word and consciously avoids talking for this reason. ${ }^{44} 46$ Examples of persistent anomia are provided by two patients described by Botez and Barbeau. ${ }^{44}$ Two weeks of total mutism were followed by a further 6 to 9 months during which their speech was hesitant with loss of fluency. Both patients were aware of their deficit: one stating that "I have to control my voice because I am missing some words", and the other "I make special efforts to recall a usual name during the conversation". Aphasia after stereotaxic surgery is usually a mild expressive or motor dysphasia, improving after 4 weeks but occasionally lasting up to 4 years. ${ }^{38}$ Hermann et al ${ }^{47}$ found that the mean size of lesions in those developing dysphasia after left sided lesions (in right handed persons) was greater than the mean size for the total group studied. Pure capsular lesions did not result in dysphasia, suggesting to the authors that a subcortical, thalamic mechanism was involved.

Psychometric studies after surgically induced thalamic lesions show mild changes, particularly in verbal performance, in the immediate postoperative period, ${ }^{48}$ but patients soon return to their preoperative level. Patients undergoing left thalamic surgery decline in verbally mediated cognitive performance more than those undergoing right sided surgery. Both anomia ${ }^{46}$ and aphasia ${ }^{38}$ are found more frequently with dominant hemisphere lesions in right handed subjects than with right thalamotomy, although anomia may follow right thalamotomy in right handed patients. ${ }^{46}$ Darley, Brown and Swenson ${ }^{49}$ found that changes in language occurred approximately twice as often in cases of left thalamotomy as with right thalamotomy and were more liable to be apparent in the older patient. Of those affected, $88 \%$ showed reduced accuracy and completeness of oral language formulation and expression, and $65 \%$ some reduction in fluency of expression. Impairments in reading comprehension, auditory retention or auditory comprehension occurred in approximately $50 \%$ of patients. In Cooper's $1961^{50}$ series, $10 \%$ of patients undergoing unilateral surgery (chemopallidectomy or chemothalamotomy) experienced speech difficulties in the first two weeks. About $20 \%$ of those affected, experienced transitory aphasia following surgery on the dominant hemisphere with spontaneous improvement within several weeks. Bilateral surgery appeared 
to "threaten" speech in a more enduring way. Among the first 100 consecutive patients, $18 \%$ experienced transitory speech abnormalities and in $6 \%$ the abnormality persisted. Even at cortical level, ${ }^{51}$ motor aphasia following penetrating injury is transient in approximately one-third of cases. By analogy, the transitory nature of the alterations in verbal functions occurring after stereotaxic thalamic operations may be due to the availability of compensatory mechanisms and the presence of small lesions within larger functional zones. ${ }^{48}$ There is abundant evidence that speech is organised asymmetrically at the thalamic level, 5253 including the provision through ventrolateral nuclei of the left thalamus of many elementary speech functions, a specific alerting response, a linkage with short term verbal memory and the appropriate respiratory changes for speech. ${ }^{54}$ Whether the acute disruption of these orderly influences non-specifically affects thalamo-cortical integrations essential for symbolic formulations, ${ }^{48}$ or whether there is direct disruption of higher language function involving thalamic connections through the centrum median and dorsal medial nuclei with Broca's area, is still a matter of conjecture.

\section{Medical treatment}

An occasional but poorly sustained improvement in articulation can follow the administration of anticholinergic drugs, especially when tremor or inertia is the predominant symptom. More dramatic is the intensification of symptoms if anticholinergic drugs are stopped suddenly; for example, Agnostini ${ }^{55}$ noted a worsening of palilalia when hyoscine was withdrawn. Amantadine does not produce a significant improvement in speech. ${ }^{56}$ However, augmentation of the dopaminergic pathways by levodopa improves the clarity of speech in most patients. Mawdesley ${ }^{57}$ states that patients speak louder and sustain phonation longer after therapy. There is little change in the rate of production of words but speech is more rapid in its initiation and phonations are shorter, crisper and separated by better pauses. Nakano et al $^{58}$ similarly report an improvement in articulatory pattern. Labial movements show shorter latency between initiation and speech, are faster and more symmetrical. Speech becomes more intelligible. Even after previous thalamotomy ${ }^{59}$ there is a general improvement in the volume and modulation of speech with levodopa. However occasional exceptions occur and dysarthria can be intensified or arise de novo.

These improvements may be sustained for several years. But the occurrence of dose-related, druginduced dyskinesias may cause fresh problems. Barbeau $^{60}$ in his review of 9 years experience of levodopa therapy, lists nearly 50 different dyskinesias. The oro-bucco-lingual and respiratory dyskinesias, in particular, may seriously hamper articulation. They include protrusion or rolling of parts of the tongue, lip clicking, smacking or gnawing, chewing or rhythmic clicking of dentures, air-hunger with panting respirations and myoclonus of diaphragm, palate or intercostals. As each of these involuntary movements may appear in combination or in isolation the variety of potential abnormalities in speech is infinite. Dyskinetic movements may be so mild that the patient is not aware of their existence. But sometimes he may be horribly aware that compulsive lip biting or asocial humming or whistling can be controlled voluntarily for only a brief moment when attention is concentrated on them and yet respond readily to a reduction in dosage of levodopa. ${ }^{20}$ Compulsive gnawing also occurs in rats g:ven levodopa ${ }^{61}$ and the instability of dopamine systems in encephalitis lethargica (cf Lesch-Nyhan hyperuricaemic syndrome) could explain reported instances of self-mutilation. ${ }^{62}$ Dose-related dyskinesias, for example laryngeal stridor, occasionally occur with amantadine. ${ }^{63}$

Continued supplementation of dopamine by levodopa therapy may hasten the rate of deterioration of Parkinsonism. 54 65 Levodopainduced abnormal movements become more persistent and a longer adjustment time is required before a beneficial effect can be obtained by lowering the dosage. The frequency and duration of oscillations in performance increase and subtle changes occur in cortical function, presaging overt dementia.64 The fluctuations-“"on-off" effectson chronic levodopa therapy can be subdivided into early morning akinesia, freezing episodes "akinesia paradoxica", end-phase deteriorations, peak-dosage dyskinesias or akinesias, and more violent, unpredictable "yo-yo-ing" swings in performance. ${ }^{66}$ Each one of these fluctuations may be accompanied by alterations in speech, not necessarily in phase with the locomotor akinesia. Indeed, the more usual pattern is for speech to be freer at the time when locomotion is most seriously affected.67 Patients often decide in advance whether to be fully mobile or able to converse freely. One patient used to smoke a cigarette before going for a walk but avoided smoking if wishing to chat. Another, barely able to whisper when visiting the out-patient department, eventually decided to omit his morning tablets, arrived stooping, rigid and requiring help to enter the room, but able to give a comprehensible account of his problems.

The onset of dementia may include subtle changes of speech. Teachers, sales-representatives and others dependent on their ability to talk, recognise a loss of 
confidence in facing an audience. Their speech and actions become dithery. Other speech difficulties become manifest with hesitations and stuttering. These manifestations are occasionally dose-related but more often there is no discernible relationship to medication. To date, the specific features of Parkinsonian dementia have not been fully documented and more information is needed on the interactions between dopamine enhancing drugs, such as levodopa and bromocriptine, and other drugs such as anticholinergics and antidepressants given in combination to ameliorate the patient's symptoms once the period of maximum benefit from levodopa has passed.

\section{Conclusion}

Many new concepts have emerged from the examination of the disorders of speech which occur in Parkinsonism. These disorders involve phonation, articulation, their central control and their integration with higher language functions such as word finding and memory. The assembly of speech production and formulation is organised asymmetrically at thalamic level. Changes in verbal performance which occur during surgically induced thalamic lesions are affected by the voluntary behaviour of the patients: "I have to control my voice because I am missing some words" and "I make special efforts to recall a usual name during the conversation". There is positive evidence that the therapeutic use of levodopa may improve speech performance, particularly phonation and articulation; but dopamineinduced side effects may affect speech in a manner not dissimilar to that following stereotaxic thalamotomy and, in their oscillation in performance, closely analagous to observations previously made of fluctuations of performance during the early stages of post-encephalitic Parkinsonism. It is pertinent that the patients were often able to exert a degree of voluntary but temporary control over these doserelated alterations of speech. Neurotransmitter substances may have a key role in speech production and assembly, not merely as part of the physical act but by influencing the rate, inflection, emotional expression and even content of speech.

\section{References}

${ }^{1}$ Selby G. Parkinson's disease. In: Vinken PJ, Bruyn GW, eds. Diseases of the Basal Ganglia. Handbook of Clinical Neurology, Vol 6. Amsterdam: North Holland Publ Co, 1968.

${ }^{2}$ Ford FR. Diseases of the Nervous System in Infancy, Childhood and Adolescence. 5th ed. Springfield: Thomas, 1966.

${ }^{3}$ Turner WA, Critchley M. Respiratory disorders in epidemic encephalitis. Brain 1925;48:72-104.

+ Jelliffe SE. Postencephalitic respiratory syndrome. Arch Neurol Psychiat 1927;17:627.

${ }^{5}$ Martin JP, Hurwitz LJ, Finlayson MA. The negative symptoms of basal ganglia disease. Lancet 1962 ;ii: 1-6 and 62-6.

${ }^{6}$ Lenneberg EH. The Biological Foundations of Language. New York: Wiley, 1967.

' Boshes B. Voice changes in Parkinsonism. J Neurosurg 1966;24:286-90.

${ }^{8}$ Luchsinger R, Arnold GE. Voice-Speech-Language. London: Constable, 1965.

${ }^{9}$ Calne DB. Parkinsonism: physiology, pharmacology and treatment. London: Arnold, 1970:19.

${ }^{10}$ Peacher WG. The aetiology and differential diagnosis of dysarthria. J Speech Hear Disord 1950;15: 252-65.

${ }^{11}$ Grewel F. Classification of dysarthrias. Acta Psychiat Scand 1957;32:325-36.

12 Hardy JC. Suggestions for physiological research in dysarthria. Cortex 1967;111:128-56.

13 Darley FL, Aronson AE, Brown JR. Differential diagnostic patterns of dysarthria. J Speech Hear Res 1969;12:246-69.

14 Darley FL, Aronson AE, Brown JR. Clusters of deviant speech dimensions in the dysarthrias. J Speech Hear Res 1969;12:462-96.

15 Parkinson J. An Essay on the Shaking Palsy. London: Whittingham and Ronald, 1817.

${ }^{16}$ Schilling R. Experimental phonetische Untersuchungen bei Erkrankung des extrapyramidalen Systems. Arch Psychiat 1925;75:419.

17 Laszewski Z. Role of the department of rehabilitation in preoperative evaluation of Parkinsonian patients. Am Geriatr $S J$ 1956;4:1280-4.

18 Nugent CA, Harris HW, Cohn J, Smith CC, Tyler FH. Dyspnoea as a symptom in Parkinson's syndrome. Am Rev Tuberculosis 1958;78:682-91.

${ }^{19}$ Khambata AS. Chapt. 5 Anatomy and physiology of voice production; the phenomenal voice. In: Critchley M, Henson RA, eds. Music and the Brain. London: Heinemann, 1977:59-77.

${ }^{20}$ Critchley EMR. Naturally occurring dyskinesias. Lancet 1970;ii:1082-3.

${ }^{21}$ Massengill R. Cinefluorographic analysis of tongue thrusting present in Parkinsonian patients. Folia phoniatr 1967;19:105-8.

${ }^{22}$ Logemann JA, Fisher HB, Boshes B, Blansky ER. Frequency and cooccurrence of vocal tract dysfunction in the speech of a large sample of Parkinsonian patients. J Speech Hear Dis 1970;43:47-57.

23 Joubert M, Barbeau A. Akinesia in Parkinson's disease. Excerpta Medica. International Congress Series. 1967;175:366-76.

${ }^{24}$ L'Hermitte J. Les formes prolongées de l'encéphalite epidemiques; formes akinétiques, formes akinétohypertoniques, formes pyschiatriques prolongées. J Med France 1923;12:143.

${ }^{25}$ England AC, Schwab RS. Parkinson's syndrome. New Eng J Med 1961;265:785-90.

${ }^{26}$ Leyser E. Die zentalen Dysarthrien und ihre Pathogenese. Klin Wochenschr 1923;47:1. 
${ }^{27}$ Leyser E. Uber einige Forman von dysarthrischen Sprachstörtugen bei organischen Erkrankungen des Zentralnerven systems. Z Neurol Psychiat 1924; 88:383.

${ }^{28}$ Critchley M. On Palilalia. J Neurol Psychopath 1927-8; 18:23-31.

${ }^{29}$ Boller F, Boller M, Denes G, Timberlake WH, Zieper I, Albert M. Familial palilalia. Neurology (Minneap) 1973;23:1117-25.

${ }^{30}$ Alajouanine T, Castaigne P, Sabouraud O, Condamin P. Palilalie paroxystique et vocalisation par lésion intéressant l'aire motrice supplémentaire. Rev Neurol $1959 ; 101: 575-96$.

${ }^{31}$ Guiot G, Hertzog E, Rondot P, Molinar P. Arrect or acceleration of speech evoked by thalamic stimulation in the course of stereotaxic procedures for Parkinsonism. Brain 1961;84:363-79.

32 Wilson SAK. In: Ninian Bruce A, ed. Neurology, Vol 1. London: Arnold, 1940:99-144.

${ }^{33}$ Sacks OW, Kohl M. Incontinent nostalgia induced by L-dopa. Lancet 1976;i:1394.

${ }^{34}$ Zutt. quoted by Jelliffe SE. In: Psychopathology of Forced Movements and the Oculogyric Crises of Lethargic Encephalitis. New York, 1932:144.

${ }^{35}$ Cooper IS. Anterior choroidal artery ligation for involuntary movements. Science 1953;118:193.

${ }^{36}$ Gillingham FJ, Kalyanaraman S, Donaldson AA. Bilateral stereotaxic lesions in the management of Parkinsonism and the Dyskinesias. Br Med J 1964; ii :656-9.

${ }^{37}$ Hassler R, Mundinger F, Riechart T. Stereotaxis in Parkinson's Syndrome. New York: Springer Verlag, 1979.

${ }^{38}$ Bell DS. Speech functions of the thalamus inferred from the effects of thalamotomy. Brain 1968;91:619-38.

${ }^{39}$ Krayenbühl H, Siegfried J, Yasargil MG. Résultants tardifs des operations stereotaxiaues dans le traitement de la maladie de Parkinsonism. Rev Neurol $1963 ; 108: 485-94$.

${ }^{40}$ Ojemann GA, Ward AA. Speech representation in ventrolateral thalamus. Brain 1971 ;94:669-80.

${ }^{41}$ Schaltenbrand G. The effects on speech and language of stereotactical stimulation in thalamus and corpus callosum. Brain Lang 1975;2:70-7.

42 Ojemann GA, Language and the thalamus: object naming and recall during and after thalamic stimulation. Brain Lang 1975;2:101-20.

43 Van Buren JM. The question of thalamic participation in speech mechanisms. Brain Lang 1975;2:31-44.

${ }^{44}$ Botez MI, Barbeau A. Role of subcortical structures and particularly of the thalamus in the mechanisms of speech and language. Int $J$ Neurol 1971 ;8:300-20.

${ }^{45}$ Ojemann GA, Fedio P, Van Buren JM. Anomia from pulvinar and subcortical parietal stimulation. Brain 1968;91:99-116.

${ }^{46}$ Ojemann GA, Hoyenga K, Ward AA. Prediction of short term verbal memory disturbances after ventrolateral thalamotomy. J Neurosurg 1971;35: 203-10.

${ }^{47}$ Hermann K, Turner JW, Gillingham FJ, Gaze RM. The effects of destructive lesions and stimulation of the basal ganglia on speech mechanisms. Confin
Neurol 1966;27:197-207.

${ }^{48}$ Riklan M, Cooper IS. Psychometric studies of verbal functions following thalamic lesions in humans. Brain Lang 1975;2:45-64.

${ }^{49}$ Darley FL, Brown JR, Swenson WM. Language changes after neurosurgery for Parkinsonism. Brain Lang 1975;2:65-9.

${ }^{50}$ Cooper IS. Parkinsonism: its medical and surgical therapy. Springfield: Thomas, 1961.

${ }^{51}$ Mohr JP, Weiss GH, Caveness WF, Dillon JD, Kistler JP, Meirowsky AM, Rish BL. Language and motor disorders after penetrating head injury in VietNam. Neurology (Minneap) 1980;30:1273-9.

${ }^{52}$ Riklan M, Cooper IS. Chapt. 8 Thalamic lateralisation of psychological functions and psychometric studies. In: Harnad S, Doty RW, Goldstein L, Jaynes J, Krauthamer G, eds. Lateralisation in the Nervous System. New York: Academic Press, 1977.

${ }^{53}$ Mateer C. Asymmetric effects of thalamic stimulation on the rate of speech. Neuropsychologia 1979;16: 497-9.

${ }^{54}$ Ojemann GA, Mateer C. Chapt. 5 Cortical and subcortical organisation of human communication. Evidence from stimulation studies. In: Steklis HD, Raleigh MJ, eds. Neurobiology of Social Communication in Primates. New York: Academic Press, 1979.

55 Agnostini C. (quoted by Critchley M, 1927 (28)). Ann del Ospedale psichiat provin in Perugia 1925;14: 111.

${ }^{56}$ Millac P, Hasan I, Espir MLE, Slyfield DG. Amantadine in Parkinson's disease. Lancet 1970;i:464.

57 Mawdesley C. Speech in Parkinsonism. In: Calne DB, ed. Advances in Neurology 3: Progress in the treatment of Parkinsonism. London: Raven, 1973.

${ }^{58}$ Nakano KK, Zubick H, Tyler HR. Speech defects in Parkinsonian patients. Neurology (Minneap) 1973; 23:865-70.

${ }^{59}$ Hughes RC, Polgar JG, Weightman D, Walton JN. L-dopa in Parkinsonism and the influence of previous thalamotomy. $\mathrm{Br}$ Med $J 1971 ; \mathrm{i}: 7-13$.

${ }^{60}$ Barbeau A. L-dopa therapy in Parkinson's disease: a critical review of 9 years experience. Can Med Assoc J 1969;101:59-68.

${ }^{61}$ Lader ML. Drug induced extrapyramidal disease. $J R$ Coll Physicians. London, 1970;5:87-98.

${ }^{62}$ Goodhart SP, Savitsky N. Self-mutilation in chronic encephalitis, evulsion of both eyeballs and extraction of teeth. Am J Med Sci 1933;185:674.

${ }^{63}$ Heathfield KWG. In: Birdwood GFB, Gilder SSB, Wink CAS, eds. Parkinson's Disease, a new approach to treatment. London: Academic Press, 1971:69.

${ }^{64}$ Barbeau A. Longterm side effects of Levodopa. Lancet $1971 ; \mathbf{i}: 395$.

${ }^{65}$ Shaw KM, Lees AJ, Stern GM. The impact of treatment with levodopa on Parkinson's disease. Quart $J$ Med 1980;49:283-93.

${ }^{66}$ Marsden CD, Parkes JD. On-off effects in patients with Parkinson's disease on chronic levodopa therapy. Lancet 1976;i :292-6.

${ }^{67}$ Critchley EMR. Peak dose dysphonia in Parkinsonism. Lancet 1976;i:544. 